\title{
Os significados da comorbidade para os pacientes vivendo com TB/HIV:
}

repercussões no tratamento

\section{1 Jacqueline Barbosa Silva, ${ }^{2}$ Gisela Cordeiro Pereira Cardoso, \\ ${ }^{3}$ Antonio Ruffino Netto, ${ }^{4}$ Afrânio Lineu Kritski I}

Resumo: O objetivo é compreender o processo de construção dos significados atribuídos pelos pacientes em relação à vivência da comorbidade tuberculose $\mathrm{e}$ HIV (TB/HIV), e sua repercussão nos respectivos tratamentos. Diante da complexidade do objeto, optou-se em estudá-lo à luz do referencial teórico do construcionismo social. O estudo qualitativo envolveu a realização de entrevista semiestruturada com dez pacientes com TB/HIV, acompanhados em um hospital na cidade do Rio de Janeiro. Os dados coletados foram submetidos à técnica de análise de conteúdo temático, organizados em cinco eixos: a) paciente e suas doenças; b) apoio; c) significados do tratamento; d) relação com o serviço de saúde; e e) estigma, preconceito e discriminação. Os resultados sinalizam que a vivência das duas condições e seus respectivos tratamentos é uma experiência difícil, trazendo sofrimento acentuado à vida dos pacientes. A TB acirra a dor do viver com HIV/Aids. O estigma da TB é reforçado pelo estigma da Aids, aumentando a vivência de medo associado ao preconceito. À família, à religião e ao serviço de saúde é atribuído papel fundamental, como lugar seguro e de preservação da identidade. Apesar do sofrimento físico, psicológico e moral e das dificuldades com ambos os tratamentos, é possível fazer conciliações no cotidiano.

> Palavras-chave: TB; HIV; TB/HIV; construcionismo social; adesão ao tratamento.

\author{
1 Faculdade de Medicina, \\ Serviço de psiquiatria e \\ psicologia médica, Hospital \\ Universitário Clementino Fraga \\ Filho, Universidade Federal do \\ Rio de Janeiro. Rio de Janeiro- \\ RJ, Brasil. Endereço eletrônico: \\ jacqsi@uol.com.br \\ 2 Escola Nacional de Saúde \\ Pública (Endemias Samuel \\ Pessoa), Fundação Oswaldo \\ Cruz. Rio de Janeiro-RJ, Brasil. \\ Endereço eletrônico: gisela. \\ cardoso@gmail.com \\ ${ }^{3}$ Faculdade de Medicina de \\ Ribeirão Preto, Universidade \\ de São Paulo. Ribeirão Preto \\ -SP, Brasil. Endereço eletrônico: \\ aruffino@fmrp.usp.br \\ ${ }^{4}$ Faculdade de Medicina, Centro \\ de Pesquisa em Tuberculose, \\ Universidade Federal do Rio \\ de Janeiro. Rio de Janeiro-RJ, \\ Brasil. Endereço eletrônico: \\ kritskia@gmail.com
}




\section{Introdução}

Tendo em vista a complexidade do tema relacionado à comorbidade tuberculose (TB)/infecção pelo vírus da imunodeficiência humana (HIV), consideramos interessante estudá-lo à luz do construcionismo social. $O$ fenômeno da comorbidade TB/HIV agrava o panorama da tuberculose, uma das mais antigas epidemias da humanidade, que juntamente com a Acquired Immunodeficieny Syndrome (Aids), surgida no final do século XX, são consideradas como grandes desafios de saúde pública. Em 2013, uma estimativa de nove milhões de pessoas desenvolveu e 1,5 milhão morreram com TB, dos quais 360.000 eram HIV positivos (WHO, 2014). Ambas afetam populaçôes menos favorecidas, vulneráveis socialmente e nas faixas etárias mais produtivas da vida, já que se trata de duas doenças transmissíveis, consideradas crônicas e com tratamentos distintos, porém semelhantes em diversos sentidos.

A TB é uma doença que tem cura. Em sua forma mais comum, a pulmonar, é transmitida no contato social, a partir da inalação de gotículas contendo bacilos expelidos pela tosse, fala ou espirro da pessoa com TB ativa (BRASIL, 2013). De acordo com Netto (2004), a desigualdade social é o componente mais importante na compreensão do problema da TB, pois esta gera pobreza e todas as suas consequências, como más condiçōes de vida, de nutrição e de educação, tornando as pessoas vulneráveis ao adoecimento.

A epidemia de Aids, por sua vez, é considerada como uma das mais graves de todos os tempos e ainda representa grande ameaça à saúde global. A Aids é uma doença ainda sem cura, transmitida via contato sexual, sangue, compartilhamento de seringas e transmissão. Contudo, grandes mudanças aconteceram nas últimas quatro décadas na história da doença. A partir de 1996, com a introdução dos antirretrovirais (ARV), os portadores de HIV/ Aids passam a conviver com uma doença crônica, que não tem cura, mas tem tratamento. Os avanços dos ARVs contribuíram efetivamente para a redução da morbi-mortalidade de HIV/Aids, alterando a natureza e a frequência das doenças oportunistas e aumentaram significativamente a expectativa e qualidade de vida das pessoas vivendo com HIV/Aids. Entretanto, surgiram outros desafios, como a adesão ao tratamento medicamentoso.

A comorbidade TB/HIV acirra a convivência dos pacientes com as duas doenças e requer terapêutica adicional, que traz consigo novos efeitos 
colaterais e interaçõos medicamentosas, demandando práticas e estratégias

na assistência específicas para o acompanhamento e adesão ao tratamento. Trata-se de duas enfermidades que a priori se aproximam pelo caráter de cronicidade e, portanto, da necessidade de cuidados específicos e de longo tempo. A medicação da TB é uma realidade que agrava o tratamento medicamentoso do HIV/Aids. $\mathrm{Na}$ TB, o uso dos medicamentos tem tempo determinado e oferece ao paciente a possibilidade de cura. O estigma é considerado na atualidade uma das questôes fundamentais no enfrentamento das duas epidemias e afeta em diversos sentidos as pessoas que vivem com a condição TB/HIV. A preocupação com a revelação de estar infectado muitas vezes é autoimposta pelo medo que o portador do HIV e da TB tem de, ao tornar conhecido seu diagnóstico, ficar sujeito a preconceitos, uma vez que ambas as doenças ainda são alvo de estigma (NEVES; REIS; GIR, 2010).

A partir da experiência da primeira autora no acompanhamento de pacientes com a comorbidade TB/HIV em um hospital universitário na cidade do Rio de Janeiro, foi possível perceber a maneira singular de sentir e vivenciar o sofrimento das duas enfermidades. Esta experiência mobilizou a reflexão sobre as práticas de assistência e pesquisa que conjugassem a subjetividade do indivíduo e sua inserção no seu contexto social. Nesse sentido, o objetivo do presente estudo é compreender o processo de construção dos significados atribuídos pelos pacientes em relação à vivência da comorbidade TB/HIV e suas repercussões no tratamento.

\section{Referencial teórico}

A opção pelo construcionismo social como referencial teórico do presente estudo justifica-se pelo fato de essa abordagem privilegiar os processos pelos quais as pessoas descrevem, explicam e/ou compreendem o mundo em que vivem, considerando o conhecimento que elas mesmas têm da realidade, construído no seu contexto cotidiano e relacional.

O construcionismo incorpora a noção de que os critérios e conceitos que utilizamos para descrever, explicar, escolher entre as opções que se apresentam são construções humanas, produtos de nossas convenções, práticas e peculiaridades (SPINK; FREZZA, 2004, p. 32). Essa forma de se colocar diante 
do conhecimento é entendida por Spink (2004) como uma concepção de que o conhecimento não é algo que as pessoas possuem em suas cabeças, e sim algo que as pessoas constroem juntas. $\mathrm{O}$ construcionismo rompe com a concepção racionalista e objetivista da ciência e incorpora um posicionamento de constante questionamento sobre o mundo em que vivemos, problematizando a noção de realidade, buscando explicações sobre as condições em que determinados acontecimentos se institucionalizam no cotidiano.

$\mathrm{Na}$ trajetória da medicina, a concepção racionalista é representada pela racionalidade biomédica, que põe ênfase no mecanismo biológico e promove um conhecimento fragmentado, especializado e reducionista do processo de adoecer, que se opõe às ideias agregadas sob o rótulo do cuidado e da integralidade. Segundo Camargo Jr. (2003), essas questões representam um obstáculo epistemológico da tecnobiociência, já que sua maior eficácia é alcançada ao reduzir completamente a experiência do sofrimento humano ao domínio biológico.

Refletindo sobre a construção social do saber no contexto saúde/doença, a perspectiva construcionista não tem por objetivo formular leis causais. A doença é vista como um fenômeno psicossocial e historicamente construído. Aproximando-se dessa perspectiva, de acordo com Foucault (1987), o saber compreende o domínio constituído pelos diferentes objetos que irão ou não adquirir um status científico; refere-se ao espaço em que a pessoa pode tomar posição para falar dos objetos de que se ocupa em seu discurso; define também o campo de coordenação e de subordinação dos enunciados em que os conceitos aparecem, se definem, se aplicam e se transformam.

Essa postura aborda a doença não apenas como uma experiência individual, mas também como um fenômeno coletivo sujeito às forças ideológicas da sociedade. Ela deixa de privilegiar a ótica da equipe de saúde como único padrão de comparação legítimo, passando a legitimar também a ótica do paciente. Portanto, possibilita o confronto entre o significado (social) da experiência e o sentido (pessoal) que lhe é dado.

Desse modo, a prioridade desse tipo de investigação é compreender as ações e práticas sociais e, sobretudo os sistemas de significação que dão sentido ao mundo, produzidos interativamente na vida cotidiana das pessoas. De acordo com Minayo et al. (1994), a atitude do pesquisador diante da realidade a ser estudada requer uma disponibilidade para aprofundar-se no mundo dos significados das 
ações e relações humanas, visando melhorar a integração do saber da equipe de saúde com o saber do paciente.

Em sintonia com a perspectiva acima mencionada, esperamos melhores resultados ao utilizarmos uma abordagem que possibilite, sobretudo a compreensão da singularidade dos significados e sentidos construídos pelo paciente em relação à experiência com a condição TB/HIV.

\section{Material e métodos}

Foi realizado estudo exploratório, de natureza descritiva, que procurou analisar os significados atribuídos pelos pacientes a respeito da vivência da comorbidade TB/HIV e suas repercussões nos tratamentos. Para isso foi empregado o método qualitativo para coleta e análise dos dados. O estudo foi aprovado no CEP do Hospital Universitário Clementino Fraga Filho da UFRJ, com o no. 208/09. Todos os entrevistados assinaram o TCLE, no qual estão assegurados confidencialidade e anonimato das informaçôes coletadas.

Participaram do estudo dez pacientes, maiores de 18 anos, que estavam em tratamento de TB e HIV ao mesmo tempo e em uso de medicamentos anti-TB por mais de 30 dias, em um hospital universitário do Rio de Janeiro. As entrevistas foram realizadas no ambulatório de $\mathrm{TB}$, localizado numa área externa ao hospital, por oferecer condições favoráveis para a privacidade do paciente, fácil acesso e estrutura física adequada, incluindo biossegurança com uso de filtro Hepa.

Para a coleta de dados, foi utilizada a entrevista com roteiro semiestruturado, com oito questôes, onde se procurou explorar a vivência do paciente em relação a ambas as enfermidades, TB e HIV, primeiro separadamente, e depois as duas juntas, e com os respectivos tratamentos. Antes do início da entrevista, foram formuladas algumas perguntas contendo dados sócio demográficos, como idade, raça/etnia, nível de escolaridade, profissão, ocupação, religião e renda pessoal. As entrevistas foram gravadas, transcritas, e duraram em média uma hora.

O roteiro de entrevista foi testado de modo a ajustar a formulação e a sequência das perguntas, assim como permitir à entrevistadora uma familiaridade e domínio do instrumento. Para a análise das respostas das entrevistas, foi utilizada a técnica de análise de conteúdo temático, que de acordo com Bardin (2000), refere-se ao desvendamento de significações de diferentes tipos de discursos, baseando- 
se na inferência, mas que, simultaneamente, respeita critérios específicos propiciadores de dados em frequência e estruturas temáticas. Segundo essa autora (BARDIN, 2000), a análise de conteúdo é um conjunto de técnicas de análise das comunicações visando obter, por procedimentos sistemáticos e objetivos de descrição do conteúdo das mensagens, indicadores (quantitativos ou não) que permitam a inferência de conhecimentos relativos às condições de produção/ recepção (variáveis inferidas) dessas mensagens.

Como forma de organizar, dar visibilidade e facilitar a análise das entrevistas construímos um mapa com colunas correspondentes aos pacientes entrevistados e as respectivas respostas às perguntas realizadas. Posteriormente, as respostas foram agrupadas de acordo com cinco eixos que surgiram a partir da primeira análise do material das entrevistas, servindo de base para as categorias de análise temática. Os eixos contemplados foram: 1) O paciente e suas doenças; 2) A importância do apoio; 3) Os significados do tratamento; 4) A relação com o serviço de saúde; e 5) O estigma: a experiência do preconceito e discriminação.

A interpretação do material consistiu em localizar os núcleos de sentido para as categorias de análise, permitindo compreender o objeto de estudo.

\section{Resultados e discussão}

O grupo entrevistado foi composto de dez pessoas ( 4 mulheres e 6 homens), com média de idade de 39 anos. A metade do grupo tinha o Ensino Fundamental (EF) incompleto, um o EF completo, três o Ensino Médio (EM) incompleto, e somente um tinha nível superior. Mais da metade (sete) era constituída por moradores da região metropolitana do Rio de Janeiro, e os demais, da Baixada Fluminense. A respeito do estado civil, quatro eram casados, dois disseram morar junto, três eram solteiros, e um separado. Em relação ao trabalho, sete exerciam atividades remuneradas, com renda média de um salário mínimo. Do total, sete eram segurados do Instituto Nacional de Seguridade Social (INSS), dois recebiam auxílio-doença, um recebia pensão e três não eram segurados. No que tange à religião, cinco designavam-se evangélicos, quatro católicos e um espírita.

Do grupo que participou da pesquisa, quatro eram pessoas que receberam o diagnóstico da comorbidade TB/HIV há no mínimo um ano e ficaram sabendo do diagnóstico do HIV ou da TB, juntos ou em períodos muito próximos. As outras seis pessoas disseram viver com Aids num período variando entre três e 
20 anos. Para este último grupo especificamente, percebemos que, apesar da experiência com uma doença grave como a Aids, o impacto de saber-se também com TB significou ter que conviver com mais uma doença difícil, depois de ter sofrido e sobrevivido ao HIV. Quanto ao primeiro grupo de quatro pessoas, saber das duas enfermidades em períodos próximos apareceu associado ao medo da discriminação e a angústia causada pela dificuldade de elaboração e aceitação de ambas as condições de doença.

\section{O paciente e suas doenças}

As falas das pessoas entrevistadas apontam para o impacto que o saber-se com TB e/ ou HIV, ou ambas simultaneamente, produziu enquanto experiências perturbadoras, principalmente relacionadas ao momento do diagnóstico. Palavras como "choque", "pancada", "baque", "assustador", "desesperador", "difícil” ou mesmo com conotaçôes de sentimentos de negação e aceitação das doenças são utilizadas:

Pensava que ia morrer só uma vez, agora eu tô pensando que eu vou morrer duas vezes. Não. É mais forte, é um sentimento mais forte, uma preocupação maior essas duas juntas. (H, 51 anos).

[...] De ter as duas doenças eu me assustei, eu tive consciência de estar tuberculoso, já depois de todo sofrimento do HIV. (H, 51 anos).

Foi o fim do mundo para mim. (H, 21 anos).

As atribuições e tonalidade das falas refletem a perplexidade, o temor e a vergonha diante do diagnóstico e convivência com a condição TB/HIV:

[...] Fiquei apavorado... Caramba! Eu tô (sic) tuberculoso e soropositivo! E agora? (H, 45 anos).

Para alguns, essa condição é considerada um castigo divino:

E deu muito medo, castigo! Tive um susto. Chegava aqui de cabeça baixa. Meu Deus, é muito castigo! (H, 51 anos).

Percebe-se que as falas refletem principalmente a dificuldade dos pacientes para aceitar a condição TB/HIV, muitas vezes marcada por experiências anteriores difíceis, vinculadas predominantemente ao HIV. Receber o diagnóstico da TB é uma condição que extrapola o ser/ou estar doente, ou com uma das doenças oportunistas que podem acometer as pessoas que convivem com HIV/Aids. A aceitação do diagnóstico, e portanto, da(s) doenças(s), torna-se estratégico, como veremos adiante, para a condução dos respectivos tratamentos. 
Identifica-se, por meio dos discursos dos pacientes, que a vivência da condição TB/Aids significa uma perda importante, tal como sinalizado na seguinte fala: "Eu caí muito! Eu perdi dois anos, vou viver só mais três" (H, 51 anos). Isso é claramente ilustrado por Cecil (2009), quando aponta uma série de experiências subjetivas que são utilizadas pelos indivíduos para se definir como doente, incluindo alterações nas funções corporais, orgânicas, até a sensação de ter sido punido por uma divindade ou relacionados ao azar e ao destino. Cecil (2009) ressalta que a doença, assim como o sintoma, podem ser vividos de modos diferentes por indivíduos de culturas, origens sociais e em contextos diferentes.

\section{A importância do apoio}

\section{Apoio da família e dos amigos}

Segundo Adam e Herzlich (2001), a maioria dos autores que trabalha buscando conhecer a influência do apoio social na saúde dos pacientes considera que ele agiria como um "amortecedor" diante das situaçôes de estresse. Como referido por Neves, Reis e Gir (2010), o apoio social é importante, porque pode amenizar o impacto das experiências estressantes vividas pelos pacientes. Por outro lado, o apoio insuficiente de pessoas que convivem no meio social, familiar ou comunitário dos pacientes parece afetar negativamente a adesão, podendo ainda levar à depressão e à desesperança.

Chama atenção o sentido atribuído pelos pacientes à importância do papel da família na dimensão do suporte emocional, do cuidado e durante o tratamento medicamentoso. Verificamos que, nos casos em que não houve suporte positivo dos familiares, os pacientes referiram sentir-se desamparados e com maior dificuldade de não cumprir o tratamento. Tanto os que vivem em um modelo de família nuclear como os que moram sozinhos ou com companheiro, de algum modo mostraram isso em suas falas:

Acho que se eu guardasse só pra mim, ia explodir. (M, 32 anos).

Se a família der apoio a gente vive mais. O apoio da família é fundamental em tudo... A família é a tua base, a tua raiz... (H, 27 anos).

Em relação à TB, inicialmente percebemos que o apoio da família é maior:

Só falei para os amigos da tuberculose, do HIV não. Eu acho que isso só cabe a mim e a minha família. (M, 42 anos). 
Muitas vezes os pacientes optam por manter sigilo sobre seu diagnóstico, o que causa o afastamento de pessoas que eventualmente poderiam dar o suporte que precisam em muitas situações durante a vivência com as duas doenças:

Se minha família soubesse seria um choque. (H, 47 anos).

Em razão de não serem aceitos pelas pessoas, e sobretudo pelo medo de causar sofrimento nas mesmas, os pacientes optam por não falar. A possibilidade de desagregação dos laços familiares requer do paciente a proteção desse vínculo considerado pela maioria como fundamental. De acordo com Cassel (1976), as chances de adoecimento e sofrimento estão diretamente ligadas à intensidade com que os vínculos sociais se desfazem e enfatizam a importância do suporte social frente ao adoecimento e também na promoção dos cuidados com o paciente, tal como na fala a seguir:

Contei somente para a minha irmã. Eu vou pra casa dela, fico lá um pouco, aí melhoro e volto pra minha casa. $(\mathrm{H}, 47$ anos).

\section{Apoio do serviço de saúde}

Os pacientes reconhecem as açôes realizadas pela equipe de saúde, com destaque para a relação profissional de saúde-paciente. Nesse cenário, os significados atribuídos pelos pacientes reforçam a importância do serviço de saúde não somente como lugar de doenças e sofrimento, mas também de interações positivas e criação de novos sentidos e maneiras de conviver com a saúde e a doença conforme as seguintes falas:

Estou bem graças à força que recebi e que encontrei no HU, as meninas do PCTH, profissionais de saúde, no grupo e companheiros. (H, 42 anos).

$\mathrm{O}$ médico me deu muita força. Fui bem tratado pelos médicos, assistente social, enfermeiro [...]. Foi a minha segunda vida aqui. (H, 42 anos).

De acordo com as afirmaçōes de Nemes (2009), o processo de enfrentamento para lidar com as limitações do tratamento é construído nos diversos espaços de interação subjetiva dos pacientes, sobretudo nos serviços de saúde.

\section{Apoio religioso}

Consideramos significativa a presença do simbolismo religioso nas falas dos pacientes ao fazerem referência a doenças e tratamentos. Na dimensão 
da doença, a fé e a religião são agentes que fortaleceriam os pacientes para o cumprimento do tratamento. A religiosidade significa encontrar um caminho que mantenha acesa a esperança e ajude a suportar o sofrimento físico e emocional diante de duas graves doenças e seus respectivos tratamentos. A maioria dos pacientes era evangélica, mas independentemente de sua religião, expressaram a importância da religião como caminho para aliviar seu sofrimento, permitindo sustentar o desejo de cura que nem sempre encontraria respaldo no discurso médico. Nos pacientes entrevistados, a religião é predominantemente vivida como algo positivo, que fortalece, como se depreende nas frases a seguir:

Estou vencendo mais uma (TB), tô (sic) com oito meses de tratamento e a Aids também, em nome de Jesus. (H, 42 anos).

Eu me sinto agradecida a Jeová por me dar forças pra não me deixar abater, porque quando a gente se abate o nosso organismo tende a coisas... Então eu me sinto bem. (M, 45 anos).

Também constatamos que, em algumas falas produzidas pelos pacientes, a religião tem o sentido de fuga e negação da doença, podendo potencializar crenças e atitudes desfavoráveis ao tratamento. Por outro lado, a evocação a uma divindade para seguir o tratamento pode aparecer como uma busca externa a uma divindade, desvinculada em alguns momentos da sua força e confiança em si mesmo.

Minha ajuda sempre é Deus. A força e fé em Deus! Deus é quem dá mais força pra gente! Eu tenho certeza que vou ficar curada de tudo isso! (M, 42 anos).

Eu ainda vou voltar aqui para contar esse testemunho! Sei que muita gente está ficando curada desse vírus, e eu também vou ficar, eu tenho certeza. (M, 42 anos).

Em estudo realizado por Pinto (2012), com pacientes portadores de enfermidades e condições médicas que estabelecem a necessidade de fazer hemodiálise, a religiosidade no tratamento não é percebida como algo substitutivo, mas complementar ao tratamento, e requer conciliação entre as crenças religiosas e as prescrições médicas.

Segundo Koening (2007), estudioso do tema religião, pesquisas sugerem que crenças e práticas podem estar associadas com maior bem-estar, melhor saúde mental e um enfrentamento mais bem-sucedido de situações de alto estresse. 


\section{Os significados do tratamento}

Em relação aos sentidos do tratamento, apareceram temas como: adesão ao tratamento, efeitos colaterais, uso de drogas ilícitas, a relação da doença e religiosidade, relação médico-paciente e o serviço de saúde.

Assim como a vivência das duas doenças é diferente entre uma e outra, a convivência com ambos os tratamentos também é diferente. Isto suscita nos pacientes a construção de significados e modos de lidar com a doença que são singulares.

No contexto geral da comorbidade TB/HIV, a não adesão a esses dois regimes medicamentosos mostra-se como uma questão comum às duas doenças e um dos maiores obstáculos à resposta positiva do tratamento individual de ambas as doenças. Nas conversas com os pacientes, fica subentendido que parte deles já abandonou o tratamento em algum momento da convivência com ambas as doenças.

Com a presença da comorbidade TB/HIV, a interação de ambos os tratamentos faz com que eles se choquem de diversas maneiras. De acordo com Neves, Reis e Gir (2010), quando acontece falência terapêutica no tratamento do HIV, o paciente fica suscetível ao aparecimento de cepas HIV resistentes aos medicamentos já existentes. Em relação à TB, quando o paciente abandona o tratamento, ele se torna importante fonte de transmissão do bacilo devido à evolução da infecção, podendo ser resistente aos medicamentos.

Quando fazem referência ao uso paralelo do medicamento das duas doenças, os pacientes mostram temor diante da intensificação dos efeitos colaterais. Apenas um paciente relata que nunca teve reação às medicações. Três pacientes fazem arranjos para administrar a tomada dos medicamentos. Os significados negativos e expectativas relativas aos medicamentos provocam no paciente muita ansiedade e medo diante da possibilidade de ficarem doentes de fato e o consequente risco de vida. Nesse caso, os remédios aparecem contraditoriamente simbolizando outra doença e ameaça à própria vida. Tomar remédio implica "sentir-se" doente (CARDOSO; ARRUDA, 2004). Ao contrário, sentir-se bem dificulta a aceitação do uso do medicamento, fato que evidencia outras formas de o paciente demonstrar desconforto com o uso da medicação que está carregado de significados (SANTOS, 2001). 
Outras questôes perpassam esse momento, tais como a dificuldade de compreensão e aceitação do esquema terapêutico, a falta de compreensão dos profissionais de saúde diante das queixas de ordem física e psicológica do paciente geradas pelo uso da medicação. Essas questôes ilustram claramente a presença de saberes e perspectivas distintas no processo saúde, doença e cuidados.

O paciente, ao mesmo tempo em que se sente saudável pela ausência de sintomas do HIV/Aids, apesar de saber-se com TB, tem que se tratar com uma medicação que o faz sentir-se doente pelos efeitos colaterais previstos por ele e percebidos como outra doença. Um paciente descreve: "Eu deixei de tomar as medicações (ARV) durante muito tempo e não consegui na $\mathrm{TB}$, não porque eu queria morrer, mas porque me fazia mal. Sobre o HIV, eu parei de tomar com a ideia de morrer" (H, 18 anos). Nesse caso, o medicamento significa para o paciente uma ameaça ao funcionamento normal do organismo e à própria vida.

De acordo com resultados de estudo sobre adesão ao tratamento HIV/Aids, atitudes de evitação e afastamento em relação ao tratamento são gerados pela construção da imagem do medicamento, provocando outra doença (CARDOSO; ARRUDA, 2004). As falas dos pacientes sinalizam algumas das contradições do tratamento que representam obstáculos para sua aceitação. O tratamento é percebido ora como aquele que lhe permite prolongar a vida, ora como algo que também lembra a doença e que pode matar:

Não tive reação, cada dia que eu tomo esse comprimido é mais um ano de vida, é isso que me da força para continuar. (M, 32 anos).

Baseando-se nas discussóes acima, entendemos que tanto a escolha pela revelação da doença como manter-se na clandestinidade geram, conforme as falas dos pacientes, sentimentos negativos e outros problemas de saúde, como a depressão. Nas entrevistas, os sintomas de uma possível depressão foram caracterizados pela produção de discursos constituídos de sentimentos de desesperança, pensamentos de morte, perda do prazer, solidão, tristeza acentuada, descrença na sua melhora e, consequentemente, não adesão ao tratamento.

O medo do paciente em ter sua identidade revelada e a criação de estratégias para tomar os medicamentos é mencionado pelos pacientes, como na seguinte fala:

[...] tenho que ir para o banheiro no trabalho para tomar o remédio escondido... eu tomo cuidado porque eu não sou assumido no trabalho de HIV, e nem na rua! (H, 51 anos). 


\section{A relação com o serviço de saúde}

As falas produzidas pelos pacientes evidenciam, sobretudo, as relações possíveis entre os pacientes e profissionais de saúde, do HU e especificamente da equipe do PCTH e do Serviço de Doenças Infecciosas e Parasitárias (DIP). Tais relações requerem um processo de construção permanente, que inclui inicialmente a valorização de uma escuta diferenciada e aceitação da singularidade do paciente - ou seja, a maneira como lidam com o tratamento a partir dos fatores relacionados a sua subjetividade e cotidiano. Nesse cenário, escutar o outro não é só ouvir os sons emitidos. "É ouvir a voz de dor e das necessidades, acolhê-la, entendê-la, compartilhá-la e devolvê-la” (FREIRE, 1996, p. 126-130). Ainda em relação à concepção de Freire: "Escutar é obviamente algo que vai mais além da possibilidade auditiva de cada um. Escutar no sentido aqui discutido significa a disponibilidade permanente por parte do sujeito para a abertura à fala do outro, ao gesto do outro, às diferenças do outro.” (p. 135).

[...] Tava direto, todo mundo dizia que era frescura minha. A assistente social que falava: não é frescura, não! Ele tá passando mal mesmo. (H, 18 anos).

A fala do paciente denota sua necessidade de ser valorizado em sua queixa, entendida por ele como sofrimento. Percebemos, pela descrição, as dificuldades de alguns profissionais para escutar e valorizar as demandas. Nessa situação, percebemos que as explicações dos sintomas se sobrepõem ao contexto, às formas como os sintomas surgem e deixando de escutar e reconhecer a ansiedade do paciente, traduzida por sua mobilização afetiva, podendo inclusive intensificar a angústia e manifestação dos sintomas.

\section{O estigma: a experiência do preconceito e discriminação}

As falas dos pacientes ilustram o quanto é desgastante emocionalmente, para a maioria, pensar e enfrentar essa questão, sentida como difícil, de intensa angústia e solidão, podendo gerar o isolamento social e restrição dos relacionamentos interpessoais. É interessante perceber como a maneira como conduzem o tratamento medicamentoso é influenciada pela preocupação dos pacientes em tornar públicas suas doenças para as pessoas com quem interagem com mais intimidade. Nesse sentido, o estigma é o motivo pelo qual os pacientes manifestam ter dificuldade de aderir ao tratamento medicamentoso e a razão para não quebrar o silêncio. Manter 
o sigilo significa, para alguns pacientes, lutar para não ocupar o lugar de doente de TB ou de Aids, garantindo assim a manutenção da sua identidade e referência anteriores à doença, tal como descrito a seguir:

O posto dava em um lugar onde tratava só tuberculose... E o medo de alguém conhecido me ver lá! "Eu rebolava" Aquela máscara de doente... Tinha que ficar. Eu achava, ah, você (sic) doente, você tá (sic) com um problema sério! (M, 47 anos).

Neves, Reis e Gir (2010) consideram que a preocupação com a revelação de estar infectado muitas vezes é autoimposta pelo medo que o portador do HIV e da TB tem de, ao tornar conhecido seu diagnóstico, ficar sujeito a preconceitos, uma vez que ambas as doenças ainda são alvo de estigma.

De maneira ambígua, os discursos dos pacientes do estudo traduziram a importância da aceitação e afeto recebido dos familiares. Contudo, chama atenção que esse comportamento aparece como algo surpreendente para os pacientes por não corresponder às expectativas e conhecimentos sobre a TB, o que denota a influência da interiorização do estigma da doença, ainda presente no imaginário social.

A perspectiva dos pacientes frente à possibilidade de ter sua doença conhecida publicamente é sentida como medo de ficar sujeito à discriminação. De acordo com Porto (2007), a estigmatização da TB expressa o "horror" diante das pessoas diante da doença, o que significa que o medo da condenação à morte moral é maior do que à condenação à morte física. Como afirmam Adam e Herzlich (2001, p. 35), a evolução das doenças crônicas interfere na mudança da autoestima do paciente, o que provoca o sentimento de vergonha pelo estado de deterioração do corpo, como descrito a seguir:

No HIV eu sofri certo preconceito; o fato de eu estar magro, esquelético... As pessoas tem medo de tocar! (H, 27 anos).

Fato interessante nas falas apresentadas por esses pacientes, percebida claramente, seria a experiência do estigma e preconceito da comorbidade TB/ HIV vivenciada de duas maneiras distintas. A primeira está relacionada à interiorização do discurso do estigma construído ao longo da história das duas doenças, relacionado às expectativas e medo de serem discriminados, podendo dificultar e atrasar a busca de ajuda, a demora do diagnóstico e tratamento, ou prejudicar a habilidade para o autocuidado e adesão ao tratamento. A outra está ligada à concretização do estigma e preconceito, ou seja, a discriminação 
propriamente dita. Neste estudo, ambas as situações aparecem com a mesma intensidade e são traduzidas por meio de comportamentos defensivos e na busca de estratégias para evitar a exposição negativa nas suas interações do cotidiano. Isto pode ser um agente motivador para a produção de novos sentidos na convivência com a comorbidade TB/HIV. Paiva et al. (2009) denominam a primeira situação de estigma efetivado (efectived stigma) e a segunda como estigma sentido (felt stigma) e acrescentam que tanto o estigma sentido, pressentido e internalizado pelo indivíduo, como a discriminação ou estigma efetivado, têm grande impacto nos desfechos de saúde e na qualidade de vida das pessoas envolvidas. Alguns exemplos do estigma sentido aparecem a seguir:

[...] eu via no olhar das pessoas, a gente sente. ( $\mathrm{H}, 51$ anos).

$\mathrm{Na}$ tuberculose, pensava: Ah! Não vão querer chegar perto e falar comigo, encontrei uma enfermeira da tuberculose na rua, ela me beijou, abraçou e me cumprimentou. (M, 32 anos).

Em relação à experiência da discriminação (estigma sentido), as falas descritas a seguir explicitam esta situação:

Contei para a namorada e ela não quer mais ficar comigo por causa do preconceito. ( $\mathrm{H}, 18$ anos).

No HIV eu sofri certo preconceito; o fato de eu estar magro, esquelético... As pessoas têm medo de tocar! O fato de eu trabalhar com o público foi o máximo de problemas que eu tive. ( $\mathrm{H}, 51$ anos).

\section{Consideraçôes finais}

A despeito do tempo de convivência dos pacientes com ambas as situações de doença, o impacto diante da comorbidade TB/HIV mostrou-se como uma experiência singular para todos eles. $\mathrm{Na}$ perspectiva do paciente, vivenciar a dupla condição de doença é uma experiência marcante, limitante, assustadora e considerada por alguns como um "castigo". Podemos afirmar que diversos fatores compõem os significados da vivência da comorbidade TB/HIV para os pacientes. Tais fatores encontram-se entrelaçados numa trama significativa. No contexto do HIV/Aids, uma questão se destacou: o impacto diante do diagnóstico. Esse aparece como um acontecimento inesperado, ou seja, os pacientes não se veem como pessoas vulneráveis ao HIV/Aids - por isso ela é considerada como doença do outro. Os pacientes mostraram que se saber HIV é uma experiência 
caracterizada pelo desespero, choque, trauma e posterior aceitação. De modo geral, as falas expressaram que o HIV/Aids é o grande vilão, uma doença muito grave, incurável: "Para sempre". E o causador da TB. Nesse sentido, viver com HIV/Aids é mais difícil do que viver com TB.

$\mathrm{A} \mathrm{TB}$, na fala dos pacientes, aparece associada à pobreza e em algumas situações a algo familiar, mas de mais fácil convivência. Entretanto, ela agrava a vivência com a condição HIV/Aids, já que torna mais difícil a vida do paciente, pode diminuir as expectativas de sobrevivência e também levantar suspeita de ser uma pessoa que tem Aids. A TB acirra a dor do HIV. Produz-se, desta maneira, a representação da TB como uma doença que acirra e agrava a vivência HIV/Aids no contexto da condição TB/HIV.

Pensando de maneira mais ampliada a relação TB/HIV, podemos afirmar que do mesmo jeito que ambas as doenças são objetivadas por meio de seus respectivos medicamentos (CARDOSO; ARRUDA, 2004), existiria na comorbidadeTB/ HIV, o HIV/Aids sendo objetivado pela TB. Isto traz para essa ligação atribuições depreciativas de cada uma das doenças: o estigma da TB reforça-se junto com o estigma da Aids, aumentando a vivência de medo associado ao preconceito.

Em diversos momentos, a convivência com ambas as situações de doença traz junto a experiência relacionada ao sofrimento diante do estigma pressentido pelo próprio paciente e não somente a discriminação propriamente dita. Podemos afirmar ser esta uma das principais razões para o sofrimento dos pacientes. $\mathrm{O}$ desgaste emocional para se proteger do preconceito e preservar a identidade moral aparece em alguns momentos como sendo maior que a dor física. Quando se trata das formas de transmissão da TB, o preconceito e discriminação são justificados pelo discurso interiorizado e reproduzido pelo paciente, da necessidade de prevenção e evitação do contato social diante da TB.

Administrar o uso concomitante dos dois tratamentos e conviver com os efeitos colaterais é algo difícil. Dessa maneira, o mal-estar sentido no corpo torna-se a própria doença. No entanto, quando conseguem conciliá-lo com o cotidiano, o sentido do autocuidado passa a ser a afirmação da própria vida. A partir dessa decisão, o paciente não se permite entregar-se à tristeza ou à possibilidade de ruptura do cotidiano. Viver torna-se importante para cumprir os papéis de provedores e cuidadores das pessoas que dão sentido a sua existência. 
Na convivência com as duas histórias de doença, observa-se a busca por maior interação social, relações afetivas com amigos, no trabalho e em espaços que possibilitem evitar a morte social e o desligar-se temporariamente das questões perturbadoras que envolvem a experiência com suas doenças. Nesse contexto, à família é atribuído o papel fundamental de um lugar seguro e de preservação da sua identidade. A religiosidade significa encontrar um caminho que mantenha acesa a esperança e ajude a suportar o sofrimento físico e emocional diante das doenças e seus respectivos tratamentos.

Quando a relação do paciente com os profissionais da saúde é acolhedora, o paciente percebe-se valorizado e fortalecido para continuar a vida e seguir o tratamento. Isto é percebido principalmente na descoberta do diagnóstico. Entretanto, é considerada uma condição necessária em todos os momentos da vida e tratamento.

Em suma, podemos afirmar que diversos significados e sentidos compõem a vivência da comorbidade TB/HIV, agindo sinergicamente e repercutindo no tratamento e vida dos pacientes. Tais significados e sentidos encontramse imbricados numa trama significativa, agravando a dinâmica das questões psicossociais, que constituem a experiência particular de ambas as condições de doença. Nos momentos em que são afetados na sua identidade moral, compreendemos que a dupla condição de doença significa a ruptura justamente do que fazia o paciente se sentir vivo, saudável, social e moralmente aceito, apesar de todo sofrimento. Esse fenômeno é representado em alguns momentos das entrevistas, quando precisamos ficar mais atentos para perceber que os significados relativos à vivência da condição TB e a condição HIV/Aids se misturavam nas falas dos pacientes, simbolizando a complexidade da experiência. Situação também observada nas contradições e ambivalências de sentimentos da experiência singular e perturbadora de ser e/ou sentir-se uma pessoa doente; doente de HIV/Aids e doente de TB, em um mesmo momento da sua existência.

Os resultados desta pesquisa reforçam a necessidade de estarmos constantemente repensando nossas práticas de saúde de maneira mais ampliada e humanizada, centrando-as na valorização da escuta ativa dos significados e experiência dos pacientes de lidar com a comorbidade TB/HIV e respectivos tratamentos. Tal experiência é permeada por um sofrimento não somente físico, 
mas moral e espiritual, localizado no contexto de suas interações sociais. Nesse sentido, consideramos que a complexidade da comorbidade TB/HIV se dá justamente pela singularidade dos significados como construção e reconstrução permanente de novas identidades; da capacidade de reinventar-se ao longo da vida e da doença. Acreditamos que, para além das semelhanças encontradas nos discursos, as reconstruções traduzem vivências únicas, que fazem parte do processo dinâmico da vida dos sujeitos da pesquisa.

Consideramos que precisamos estar mais afinados com as demandas do paciente, aprimorar nossa escuta para um atendimento caracterizado pela autenticidade do encontro e sem defesas, o que não significa que não estamos fazendo uso da ciência ou estamos reduzindo o valor de nossas ações de saúde. Ao contrário, dessa maneira estamos evitando a falta de confiança e o distanciamento. Estamos incluindo novas formas de pensar e fazer em saúde e construindo condiçōes favoráveis a uma assistência de qualidade, com resultados positivos.

Por fim, ressaltamos que todos os conteúdos expressos nas falas dos pacientes são relevantes, uma vez que fazem parte do processo de construção e reconstrução permanente de suas vidas com ambas as doenças, numa dimensão que não se esgota nos objetivos desta pesquisa.

\section{Sugestôes}

Diante dos relatos de sofrimento que foram trazidos pelos pacientes que vivem com a comorbidade TB/HIV e da urgência para lidar com a coepidemia, consideramos importante a articulação dos serviços de atenção à TB e HIV/ Aids, bem como a abordagem multidisciplinar e contínua. Tendo em vista que a relação do paciente com a equipe de saúde é um processo relacional, permeado por forte conteúdo emocional, sugerimos que pacientes e profissionais encontrem nos serviços de saúde um ambiente de acolhimento favorável à construção de possibilidades que minimizem o sofrimento. Além disso, consideramos necessário atentar para a manutenção do sigilo e a privacidade, elementos cruciais por se tratar de pessoas que convivem com o preconceito e discriminação de ambas as doenças no seu cotidiano.

Sugerimos o desenvolvimento de estratégias de educação continuada para os profissionais de saúde que atendem aos pacientes com TB/HIV, visando ao atendimento integral; a intensificação da sensibilização e respeito dos profissionais em relação 
às queixas e reação de ordem física e psicológica geradas pela relação com a doença tratamento e as maneiras escolhidas pelo paciente em resolver seus problemas.

Por fim, acreditamos ser fundamental valorizar as dimensões da pessoa, suas concepções a respeito do que sente; seus preconceitos e expectativas em relação a doença e tratamento, sofrimentos, crenças e dinâmica das suas relações sociais, inclusive os silêncios que são carregados de significados. ${ }^{1}$

\section{Referências}

ADAM, P.; HERZLICH, C. Sociologia da doença e da medicina. Bauru: EDUSC, 2001.

BARDIN, L. Análise de Conteúdo. Porto: Ediçōes 70, 2000.

BRASIL. Ministério da Saúde. Programa Nacional de Controle da Tuberculose. Departamento de DST/Aids e Hepatites Virais. Coinfeç̧ão. Disponível em http://www. aids.gov.br/tags/tags-do-portal/coinfecção. Acesso em: 16 jul. 2013.

. Ministério da Saúde. Secretaria de Vigilância em Saúde. Programa Nacional de Controle da Tuberculose. Manual de Recomendações para o Controle da Tuberculose no Brasil. Brasília: Ministério da Saúde, 2010.

Ministério da Saúde. Secretaria-Executiva. Manual de Recomendações para o manejo da coinfecção TB-HIV em serviços de atenção especializada a pessoas vivendo com HIVI AIDS. Brasília: Ministério da Saúde, 2013.

CAMARGO JR, K. R. Um ensaio sobre a (In)definição de integralidade. In: PINHEIRO, R.; MATTOS, R.A(Org.) Construção da Integralidade: cotidiano, saberes e práticas em saúde. Rio de Janeiro; IMS-UERJ, 2003. P 35-41.

CARDOSO, G.C.P.; ARRUDA, A. As representaçôes sociais da soropositividade e sua relação com a observância terapêutica. Ciência \& Saúde Coletiva. Rio de Janeiro, v. 10, n. 1, p. 151-62, 2004.

CASSEL, J. The contribution of the social environment to host resistance: the Fourth Wade Hampton Frost Lecture. AmJ Epidemiol., v. 104, n. 2, p. 107-23, 1976.

FOUCAULT, M. A arqueologia do saber. Rio de Janeiro: Forense Universitária, 1987.

FREIRE, P. Pedagogia da autonomia: saberes necessários à prática educativa. São Paulo: Paz e Terra, 1996.

KOENING, H.G. Religião, espiritualidade e psiquiatria: uma nova era na atenção à saúde mental. Rev. Psiquiatra. Clin. São Paulo, v. 34, supl. 1, p. 5-7, 2007.

MINAYO, M.C.S. et al. Pesquisa social: teoria, método e criatividade. Petrópolis: Vozes, 1993. NEMES, M.I.B. Desenvolvimento da Linha de pesquisa Qualiaids. 2009. Tese (LivreDocência) - Faculdade de Medicina, Universidade de São Paulo, São Paulo, 2009. 
NEVES, A.S.; REIS, R.K.; GIR, E. Adesão ao tratamento por indivíduos com a coinfecção HIV. Rev. Esc. Enferm. Ribeirão Preto, v. 44, n. 4, p. 1135-41, 2010.

PAIVA, V.; ALONSO, L. Em tempo de AIDS: viva a vida. In: PAIVA, V. Em tempos de Aids. São Paulo: Summus, 1992.

PINTO, N.A. Entre a máquina e a fé: pacientes em um programa de hemodiálise. Orientadora: Professora Brígida Morais Falcão. Dissertação (Mestrado em Educação em Ciências e Saúde) - Universidade Federal do Rio de Janeiro, NUTES, Rio de Janeiro, 2013. PORTO, A. Representações sociais da tuberculose: estigma e preconceito. Rev. Saúde Pública. São Paulo, v. 41, supl. 1, p. 43-9, 2007.

RUFFINO NETTO, A. Carga da tuberculose e reflexões sobre o tema. Editorial. Jornal Bras. Pneumol. Brasília, v. 30, n. 4, p. 307-309, 2004.

SANTOS, D.F. Vivendo com HIVIAids: cuidado, tratamento e adesão na experiência do grupo Com Vida. Dissertação (Mestrado em Saúde Coletiva) - Instituto de Medicina Social, Universidade do Estado do Rio de Janeiro, Rio de Janeiro, 2001.

SPINK, M.J. (Org.). Práticas discursivas e produção de sentidos no cotidiano: aproximações teóricas e metodológicas. São Paulo: Cortez, 2004.

SPINK, M.J.; FREZZA, M.R. Práticas discursivas e produção de sentidos: a perspectiva da Psicologia social. In: SPINK, M.J. (Org.). Práticas discursivas e produção de sentidos no cotidiano: aproximações teóricas e metodológicas. São Paulo: Cortez, 2004. p. 32-35.

UNAIDS, HIV e tuberculose: a tuberculose e o SIDA, ponto de vista da ONOSIDA. Disponível em: https://14minionuunaids 2001.wordpress.com/2013/04. Acesso em: 25 maio 2014.

WORLD HEALTH ORGANIZATION. Global Tuberculosis Report 2014. Geneva: WHO, 2014.

\section{Nota}

1 Este artigo é resultado de dissertação de mestrado defendida no Programa de Pós-Graduação em Clínica Médica da Faculdade de Medicina da UFRJ, em março de 2014. J.B. Silva e G.C.P. Cardoso participaram da concepção do estudo, análise e interpretação dos dados, e redação do artigo. A. Ruffino Netto participou da concepção e revisão crítica do artigo. A.L. KRITSKI realizou revisão crítica do conteúdo e do artigo. 
The meanings of comorbidity for patients living with TB / HIV: implications in the treatment This article aims to understand the construction process of meanings given by patients in relation to the experience of comorbidity tuberculosis and HIV (TB / HIV), and its impact on their treatments. Given the complexity of the subject, it was decided to study it in the light of the theoretical framework of social constructionism. The qualitative study involved the use of semi-structured interviews with ten patients with TB / HIV being treated at a hospital in the city of Rio de Janeiro. Data were examined with content analysis technique, organized into five areas: a) patient and their disease; b) support; c) treatment meanings; d) relationship with the health service; and e) stigma, prejudice and discrimination. The results indicate that the experience of the two conditions and their treatment is a difficult experience, bringing marked distress to patients' lives. TB intensifies the pain of living with HIV / AIDS. The stigma of $\mathrm{TB}$ is reinforced by the stigma of AIDS, increasing the fear of living associated with prejudice. To the family, religion and health services are entrusted key role as a safe place and identity preservation. Despite the physical, psychological and moral suffering and difficulties with both treatments, it is possible to make compromises in everyday life.

Key words: TB; HIV/Aids; comorbity; treatment; paper. 